\title{
La Humanae Vitae como denuncia de las sociedades opulentas
}

\author{
POr JAVIER GOROSQUIETA
}

Han pasado ya cerca de siete años desde la publicación de la encíclica de Pablo VI Humanae Vitae, sobre el control de la natalidad. Se acallaron bastante los ecos de la tremenda polémica de opiniones que a escala mundial promovió. Si intentamos hoy volver sobre la misma es, sobre todo, por dos motivos: el primero, porque, en cuanto afecta a las relaciones sexuales de la pareja humana vinculada por el matrimonio, creemos poder ofrecer una solución madura y liberal, aun dentro de la ortodoxia católica; el segundo, porque en los innumerables comentarios vertidos sobre la Mumanae Vitae, creemos se han descuidado relativamente sus importantísimos aspectos económicos, sociales y políticos.

La vertiente sexual privada del documento, en cuanto afecta al control de la fecundidad por parte de la pareja humana, es explorada por Benjamín Forcano en artículo que publica este mismo número de la Revista. Aquí me fijaré en su ladera más crítica y renovadora: la que afecta a la política demográfica.

Distanciados un tanto en el tiempo de aquel 25 de julio de 1968, en que el Papa puso su firma y promulgó la encíclica, es ciertamente aleccionador volver de nuevo sobre la barahúnda de comentarios que entonces se promovieron, intentar encontrar criterios válidos de sistematización de estos últimos y proceder a la misma efectivamente. $Y$ es realmente interesante topar con que la homogeneización se produce cuando agrupamos las reacciones por referencias geográficas, económicas y políticas.

Más en concreto, en cuanto a sus aspectos políticos y sociales, la Humanae vitae encuentra una acogida claramente positiva en Latinoamérica, en Africa y en los países del Este europeo satélites de Rusia; una acogida crítica, en los países 


\section{J. GOROSOUHETA}

desarrollados de Occidente; una actitud reticente, en Rusia, y contradictoria, en el área subdesarrollada del sudeste asiático.

La conclusión podría ser clara: en el aspecto que abordamos, y hablando en términos generales, nadie ha visto con serenidad el documento, sino, más bien, desde el prisma de sus propios intereses.

Comenzaré por ofrecer, en primer lugar, los dos párrafos clave de la Humanae Vitae que provocaron el "escándalo": "... debemos, una vez más, declarar que hay que excluir abso. lutamente, como vía lícita para la regulación de los nacimientos, la interrupción directa del proceso generador ya iniciado, y sobre todo el aborto directamente querido y procurado, aunque sea por razones terapéuticas.

"Hay que excluir, igualmente, como el Magisterio de la Iglesia ha declarado muchas veces, la esterilización directa, perpetua o temporal, tanto del hombre como de la mujer; queda, además, excluida toda acción que, o en previsión del acto conyugal, o en su realización, o en el desarrollo de sus consecuencias naturales, se proponga, como fin o como medio, hacer imposible la procreación» (núm, 14).

El texto de la Humanae Vitae que más directamente se refiere a la política demográfica es el siguiente: "Somos conscientes de las graves dificultades con que tropiezan los poderes públicos a este respecto, especialmente en los pueblos en vías de desarrollo. A sus legítimas preocupaciones hemos dedicado la encíclica Populorum Progressio. $Y$ con nuestro predecesor, Juan XXIII, seguimos diciendo: "Estas dificultades no se superan con el recurso a métodos y medios que son indignos del hombre y cuya explicación está sólo en una concepción estrechamente materialista del hombre mismo y de su vida. La verdadera solución solamente se halla en el desarrollo económico y en el progreso social, que respeten y promuevan los verdaderos valores humanos, individuales y sociales"» (núm. 23).

Veamos ahora, a nuestro propósito, algunas muestras típicas de las diferentes líneas de comentarios a que aludí arriba.

\section{EN EL OCCIDENTE ECONOMICAMENTE DESARROLLADO}

Escribió The Economist en uno de sus artículos editoriales:

"La encíclica de Pablo VI sobre el control de natalidad úni" camente cabe describirla como una tragedia para el mundo y un desastre para la Iglesia Católica Romana. Es una tragedia para el mundo, porque aumentará la infelicidad de las mujeres 
católicas obedientes (cuyo estado la encíclica afecta proteger, pero de cuyos problemas reales la masculina Curia Romana se ha mostrado de nuevo lamentablemente lejana), $y$, además, porque creará nuevas y grandes dificultades en muchas regiones en desarrollo.

"Es posible que el mundo pueda soportar por algún tiempo todavía su actual tasa de crecimiento de la población, de un 2 por 100 anual, aunque esto supondrá que se doblará el número de sus habitantes en un periodo de treinta y cinco años. Pero es completamente cierto que algunos países en desarrollo no pueden asimilar sus presentes explosiones demográficas; no tanto por las dificultades consecuentes en el suministro de alimentos, sino, más bien, por la presión que las crecientes oleadas de juventud ejercerán sobre la educación, que es el más escaso y vital recurso de toda nación en desarrollo" (The Economist, 13 de agosto de 1968).

Con parecida emotividad y dureza manifestó su opinión y, en este caso, también su protesta un grupo de dos mil seiscientos científicos y estudiosos de los Estados Unidos. Decían, entre otras cosas:

"Los científicos firmantes protestan vehementemente contra la encíclica del Papa Pablo VI. Humanae Vitae, sobre el control de los nacimientos. Más de la mitad del Globo padece hambre y sus condiciones sociales están empeorando rápida y quizá irreversiblemente. La amenaza de una pestilencia a escala mundial aumenta cada día, a medida que crecen la desnutrición y superpoblación, y los medios de transporte entre los varios continentes podrán favorecer que se propague una epidemia de un extremo al otro del Globo. De otra parte, las presiones demográficas contribuyen a las tensiones políticas y aumentan la posibilidad de una guerra bacteriológica y termonuclear. Cualquier acción que bloquee los esfuerzos para detener el desarrollo numérico de la población mundial perpetúa la miseria en que realmente viven millones de hombres, mientras no hace imposible la muerte por hambre de un número todavía mayor en los próxímos decenios. El descubrimiento de la matanza de seis millones de hebreos durante la segunda guerra mundial empuja al pueblo civilizado a mezclar en la culpa a quienes no estaban directamente implicados en las ejecuciones. Pero ¿qué decir de las vidas destrozadas y de las lentas y prolongadas muertes de un número igual de personas que no tienen suficiente comida? El hecho de que el Papa se vea obligado por sus convicciones religiosas a adoptar semejante posición, ihace menos horrible estas muertes que las causadas por motivos políticos? Nosotros creemos que no."

Como se puede apreciar, aun los científicos perdieron la se- 
renidad ante el comentario; lo cual, por otra parte, no aporta mayor razón a sus ideas; si de algo se puede sospechar, es, pues, más bien de lo contrario.

No podemos, ni queremos, multiplicar las citas, ni ahora ni en los apartados que siguen. Pero si creemos haber hecho un esfuerzo por recoger, en cada grupo, las que creemos más típicas y representativas en líneas generales.

\section{EN AMERTCA LATHA}

Reacción totalmente positiva de dom Helder Cámara, arzobispo de Recife, en Brasil:

"Las masas latinoamericanas, asiáticas, africanas estarían muy pronto embuchadas y ahogadas por las píldoras contraceptivas, si Pablo VI no hubiese elaborado la encíclica Humanae Vitae. Jamás olvidaré las palabras del presidente americano Lyndon Johnson, cuando afirmó: "cinco dólares gastados para el control de los nacimientos son mucho más lucrativos que cien dólares gastados en favorecer el desarrollo". Por eso quedo agradecido a Pablo VI por su encíclica, aunque reconozco que podrá crear problemas para los países en vías de desarrollo."

Es, sí, nota característica en la reacción suramericana el considerar la propaganda anticonceptiva como un arma más del imperialismo americano. Veamos otro testimonio:

"La Humanae Vitae lleva fecha del 25 de julio, pero se ha publicado el dia 29. En este mismo día, el presidente Lyndon Johnson firmó una ley para la ayuda a los países en vías de desarrollo, en la que se preveían planes para el control de natalidad. La desgraciada decisión del Gobierno de Washington no parece nueva. Corresponde a una campaña sistemática, envuelta en un halo de superflación y de dólares, que priva a millones de hombres del derecho de procreación. Es verdad que el creciente des. arrollo demográfico plantea a los Gobiernos agudos problemas. Pero llegar al control sistemático de la natalidad de los pueblos como solución ideal... es como proponerse la eliminación de los inválidos; de los anormales y de los ancianos, porque no prestan una contribución valiosa material a la sociedad. El materialismo, el egoísmo y el error se enroscan agresivamente en un único error que ya no podía permanecer escondido por más tiempo" (1).

En la misma crítica envuelven los latinoamericanos la política extorsionista del Banco Mundial y de su presidente McNamara:

(1) Federico Prieto, en La Prensa, de lima, 2 de agosto de 1968. 
"Diversas personalidades, como asimismo organismos cató. licos, se han pronunciado contra la propuesta del presidente de la Banca Mundial, Robert McNamara, que ha ofrecido ayuda de este instituto de crédito para el control de la natalidad. El presidente boliviano, René Barrientos, ha subrayado cómo en su país no se puede aplicar el control de la natalidad, "porque mi Gobierno es contrario a la tesis de McNamara". Una encuesta realizada por el Diavio, de La Paz, llegó a la conclusión casi unánime de que la propuesta de McNamara "es intolerable". Un grupo de médicos y biólogos católicos declaró que McNamara lanza "una ofensiva ofreciendo la venta de la conciencia católica boliviana a cambio de generosos créditos". A su vez, Radio Fides calificaba este condicionamiento como un evergonzoso mercado"; mientras el diario Presencia, de La Paz, declaraba: "Por muy grave que sea el problema de la explosión demográfica, no debe resolverse con el uso de aquellos medios que nos han ofrecido el resultado de "ghetos" negros en los Estados Unidos; medios que suponen que nosotros, hombres y mujeres del mundo subdesarrollado, podemos ser "planificados" como las bestias" (2).

\section{EN AFRICA}

La mentalidad tradicional africana de respeto a la vida y a la fecundidad fue terreno abonado que asimiló con naturalidad, en términos generales, la doctrina demográfica de la Humanae Vitae. Escriben así, por ejemplo, dos periodistas del Camerún:

"En una sociedad en la que los valores supremos son el culto de la vida, el aprecio de la fecundidad, el amor apasionado por los niños y el respeto a la mujer como depositaria sagrada de la vida, una política de la píldora no podría practicarse sin contradecir a estos valores fundamentales y sin introducir un des. equilibrio en la vida de dicha sociedad. Para nosotros los africanos, los negro-africanos, la vida es doblemente sagrada. Está consagrada por la fuente, que es Dios, causa primera de toda vida. Lo es también por su ordenación a asegurar la continuidad de los vivientes en la línea ancestral de los muertos, que nosotros creemos reunidos con Dios... Nosotros permaneceremos fieles a nuestros valores fundamentalmente humanos para realizar esta misión altamente divina, o no estaremos en condiciones de cumplirla." "El problema del subdesarrollo es un problema humano, moral, no solamente económico, material. El Papa es quizá el único que puede comprenderlo bien, ya que él enseña el desarrollo integral de todo el hombre... En vez de quererse esterilizar con los píldora, los ricos obrarian mucho mejor

(2) Encuesta IDOC, dirigida por F. V. Joannes y editada en español por Ed. Marfil, S. A., Alcoy (Valencia), 1970, pág. 243. 


\section{J. GOROSOUIETA}

satisfaciendo nuestras justas reivindicaciones económicas, que siempre se van aplazando sine dien (3).

\section{EN POLONIA, CHECOSLOVAQUIA, RUSIA}

Las voces que conocemos de la lglesia de los países saté. lites y de Yugoslavia son acogedoras y a veces entusiastas de la línea demográfica de la Humanae Vitae.

En Polonia, la Iglesia se encuentra enfrentada con el Gobierno a causa de una legislación muy liberal para reducir el índice de crecimiento de la población; el aborto se practica legalmente en los hospitales y se ha hecho una intensa propaganda en favor de los anticonceptivos. Frente a esto, el cardenal Siephan Wyszynski manifestó los sentimientos de la Iglesia polaca, cuando declaró: "La nación polaca ha acogido la encíclica con un grande alivio, convencida de que la enseñanza de la lglesia no puede ser otra, y que tampoco puede ser otra la palabra del Papa... Es necesario salvar los valores preminentes de la vida y la cultura humana, para evitar que, con el triunfo del egoismo y del amor a la comodidad, se convierta la Humanidad en un conjunto de enanos, imbéciles y degenerados."

En Checoslovaquia, escribía así el diario Druzina* "El Papa, en la encíclica, ha dicho que la vida humana es sagrada y que, por lo mismo, debe ser digna del máximo respeto... En este sentido añadimos que las palabras del Papa eran necesarias incluso para nosotros y para nuestra situación en Eslovenia... $\mathrm{Si}$ atendemos al indice de natalidad de nuestra patria y entre nuestros compatriotas en el extranjero, quedamos convencidos de que la enciclica del Papa sobre la transmisión de la vida y sobre la nobleza del vínculo matrimonial producirá efectos beneficiosos para nuestro pueblo. También entre nosotros hay hombres pertenecientes a otras concepciones ideológicas que quie. ren purificar cuanto hay de insano en nuestra vida social; pensa. mos que esta obra puede constituir verdaderamente un fecundo terreno para el diálogo."

Piensa, pues, el periodista esloveno que el incremento demográfico supuestamente esperado como efecto de la Humanae Virae no puede ser sino beneficioso para Eslovenia y que en esto podría haber acuerdo con los dirigentes comunistas, "hombres pertenecientes a otras concepciones ideológicas, que quieren purificar cuanto hay de insano en nuestra vida social".

En Rusia no se ha producido un ataque frontal a la Humanae Vitae. Probablemente, es verdad, porque en un sistema de abso-

(3) Encuesta IDOC, o. C., págs. 294, s. 
luto control de los medios de opinión pública tal ataque frontal resulta innecesario. Pero tampoco se ha tomado a la encíclica como blanco de propaganda antirreligiosa. Algunos medios intelectuales, como el que se expresa en la Literatumaya Gazeta, defienden la píldora en su crítica de la Humanse Vitae, pero por la peregrina razón de que "el Papa condena a millones de mujeres al aborto. Sólo un hombre malvado y cruel-dice--puede impedir el uso de los métodos anticonceptivos eficaces e mofensivos" (4). En realidad, esta crítica más parece un pretexto que otra cosa. Téngase en cuenta que, según ese mismo artículo, las tres cuartas partes de las mujeres rusas que practican el control de los nacimientos recurren todavía al aborto, permitido por la ley, a condición de que se realice en hospitales y que la gravidez no haya superado los tres meses; la píldora, por el contrario, estaba prohibida. De esta forma, la supuesta critica contra el Papa se vuelve en realidad contra los dirigentes politicos soviéticos, "malvados y crueles", que empujan al aborto legal, a la intervención quirúrgica peligrosa, por no permitir la pildora. Por otra parte, Rusia tiene actualmente un indice muy bajo de natalidad, menor que el europeo. Ante la inmensidad de sus espacios geográficos y la presión demográfica china, se comprende no esté interesada en la crítica de un documento que parece apoyar, al menos indirectamente, el alza en la tasa de nacimientos.

\section{MAS OUE CONTROL DE NATALDAD, SOLIDARIDAD EN EL DESARROLLO}

Ante este breve recorrido de opiniones típicas por zonas geográficas, nivel de riqueza y sistemas económicos, no puede uno menos de sorprenderse de que los países opulentos de Occidente, los de la acre actitud crítica, manifiesten adoptar esta postura por razones humanitarias en relación con el Tercer Mundo, con un Tercer Mundo en que la encíclica recibió más bien una favorable acogida. ¿Es que los del Tercer Mundo están ciegos? ¿Son acaso masoquistas? ¿Celo magnífico de los ricos por el bien de las áreas marginadas?

Si esto último fuera lo cierto, les recordariamos las siguientes palabras de Juan XXIII, en su encíclica Mater et Magistrin, palabras que hace también suyas la Humanae Vitae (núm. 23), como indiqué al principio:

"La verdadera solución (del problema demográfico) se halla solamente en el desarrollo económico y en el progreso social, que respeten y promuevan los verdaderos valores humanos, individuales y sociales; es decir, desarrollo económico y progreso

(4) Encuesta IDOC, o. c., pág. 320. 
social, actuados en el ámbito moral, en conformidad con la dignidad del hombre y con el inmenso valor que es la vida de cada uno de los seres humanos, y actuando en una colaboración a escala mundial que permita y fomente una circulación ordenada y fecunda de útiles conocimientos, de capitales y de hombres" (número 192).

¿Acaso conocemos un solo país desarrollado con una demasiado elevada tasa de natalidad? Colaboremos al desarrollo de la periferia mundial en sentido económico; colaboremos, no con una economía de cuentagotas, sino creando a escala mundial las condiciones para ritmos elevados de crecimiento en las zonas pobres, y el problema demográfico se resolverá-la experiencia de los países ricos lo demuestra-por sí sólo. Por paternidad responsable, por cultura, incluso, si queremos, por egoísmo, la tasa de natalidad caerá a los límites que ahora consideramos normales. La Humanae Vitae patrocina el desarrollo; sólo se opone a nuestra estrategia imperialista de propaganda anticonceptiva.

\section{LA EXPERIENCIA DE LA INDIA}

Creo interesante la experiencia de este populoso país del Tercer Mundo, en el que vive y se agita casi la sexta parte de la población mundial. En él, el problema demográfico adquiere proporciones gigantescas: una densidad de población de 178 habitantes por kilómetro cuadrado, ocho veces superior a la media de la Tierra; un aumento demográfico de 108 millones largos de habitantes en el decenio 1961-1971; una tasa actual de natalidad del 39,8 por 1.000 , más de dos veces la de Europa o Estados Unidos; un desarrollo anual del producto nacional bruto en un 6 ó un 7 por 100 , pero que, por causa del crecimiento demográfico, apenas sirve para otra cosa que para mantener a la población en su mísero nivel medio de vida, en unos ingresos medios por cabeza de 90 dólares anuales (con niveles de precios parecidos a los españoles], etc.

Pues bien, el Gobierno se decidió, ya desde 1951, por una fortísima política de "family planning", en el sentido de una masiva propaganda de limitación de nacimientos. En 1972-73 funcionaban en la India 1.952 centros urbanos, 5.182 centros rurales y 32.217 delegaciones de tales centros para la esterilización y el adoctrinamiento sobre el control de natalidad. El Gobierno habla de haber logrado hasta el momento la esterilización de más de 14 millones de personas, la inserción IUCD en cerca de cinco millones; promueve la venta de preservativos para varones, manifestando como uno de sus logros el haber pasado de una venta o regalo, según los casos, de 60 millones de tales 
medios, en 1968-69, a 79 millones, en 1972-73. Hay muchísima propaganda mural, a todo color-la he podido ver-, con la consabida leyenda: "Familia pequeña, familia feliz". Se ha llegado ya a la abierta propaganda oficial para el aborto: "El aborto es legal, no encierra peligro, se realiza con discreción", dice el anuncio que pasan en los cines durante el intermedio de la película. Da claramente la impresión de una lucha a la desespe. rada, saltando ya por encima de todos los escrúpulos morales.

El Gobierno descubre los resultados que cree haber obtenido: haber reducido la tasa de natalidad desde el 41,7 por 1.000 , en 1951-60, al 39,8 por 1.000, en 1961-70 (5). Precarios, muy precarios resultados para tan gran esfuerzo; resultados que, desde luego, no resuelven el problema, sino que lo dejan prácticamente intacto.

Magnífico ejemplo, pues, el de la India, a nuestro propósito: ha fracasado allí rotundamente la política de control de natalidad. Unicamente cuando este país se desarrolle significativamente-y sólo lo podrá hacer sobre la base de una solidaridad internacional-, podrá liquidar su espantoso problema demográfico; este problema que no sólo inquieta al indio culto o político, sino que, al parecer, desasosiega también el sueño de las sociedades opulentas.

Terminemos con otras palabras de Pablo Vl en su encíclica Populorum Progressio: "El deber de solidaridad de las personas es también el de los pueblos: los pueblos ya desarrollados tienen la obligación gravísima de ayudar a los países en vías de desarrollo. Se debe poner en práctica esta enseñanza conciliar. $\mathrm{Si}$ es normal que una población sea el primer beneficiario de los dones otorgados por la Providencia como fruto de su trabajo, no puede ningún pueblo, sin embargo, pretender reservar sus riquezas para su uso exclusivo. Cada pueblo puede producir más y mejor, a la vez para dar a sus súbditos un nivel de vida verdaderamente humano y para contribuir también al desarrollo solidario de la Humanidad" (núm. 48).

(5) Cfr. India 1974, Anuario del Ministerio de Información y Radio de la India, págs. 1 a 6 y 90 a 106 . Ver también, en este mismo número de Rev de FOMENTO SOCIAL, mi artículo: Un gran país entre la esperanza y el caos: La India, 1975. 